\title{
Data mining and accelerated electronic structure theory as a tool in the search for new functional materials
}

\author{
C. Ortiz ${ }^{1}$, O. Eriksson ${ }^{2}$, M. Klintenberg ${ }^{*, 3}$ \\ Department of Physics and Materials Science, Uppsala University, Box 530, SE-751 21 Uppsala, Sweden
}

\section{A R T I C L E I N F O}

\section{Article history:}

Received 29 April 2008

Received in revised form 2 July 2008

Accepted 15 July 2008

Available online 2 September 2008

\section{PACS:}

29.40.Wk

71.20.Mq

71.15. $-\mathrm{m}$

Keywords:

Electronic structure theory

Data mining

Scintillating materials

\begin{abstract}
A B S T R A C T
A highly accelerated electronic structure implementation and data mining algorithms have been combined with structural data from the inorganic crystal structure database to generate materials properties for about 22,000 inorganic compounds. It is shown how data mining algorithms employed on the database can identify new functional materials with desired materials properties, resulting in a prediction of 136 novel materials with potential for use as detector materials for ionizing radiation. The methodology behind the automatized $a b$ initio approach is presented, results are tabulated and a version of the complete database is made available at the internet web site <http://gurka.fysik.uu.se/ESP/> (Ref. [1]).
\end{abstract}

(C) 2008 Elsevier B.V. All rights reserved.
Sensors, solar cells, advanced batteries, and magnetic strips in credit cards are examples of functional materials present in every-day life. One important task for the research in materials science is the continuous improvement and discovery of new such advanced materials. Ab initio electronic structure calculations as a tool for predicting materials properties have steadily increased in use over the years [2] and play today an important role due to the relatively inexpensive and versatile guidance it offers. There are currently some 8000 studies published annually with this method.

Electronic structure theory applied in materials research is typically done in a fashion where a calculation follows, or accompanies, an experimental result. Knowledge on an atomistic level is thus gained which can help in understanding the experimental results [3]. In some rarer cases the theoretical calculations predict a materials property which subsequently may be realized experimentally. An example of the latter is the newly proposed tetragonally distorted FeCo alloy with exceptional out of plane magnetic anisotropy [5,4]. These materials simulations are done in a oneby-one mode, where one calculation accompanies one experiment.

\footnotetext{
* Corresponding author.

E-mail addresses: olle.eriksson@fysik.uu.se (O. Eriksson), Mattias.Klintenberg@ fysik.uu.se (M. Klintenberg).

1 Partly affiliated at Lawrence Berkeley National Laboratory, Berkeley, California during years 2002-2005.

2 Tel.: +4618 4713625; fax: +46184713524.

3 Partly affiliated at LBNL during years 1998-2005.
}

However, with an increasing demand of an accelerated speed in finding or predicting new materials this may not be the most efficient approach. Alternatives to this methodology have indeed been discussed, for instance, numerical algorithms which obey evolutionary principles borrowed from biology have been applied to find structural data of compounds and alloys [6], and in a somewhat similar study where formation probabilities derived from correlations mined for in experimental data were used to guide $a b$ initio calculations for unknown structures [7].

In this article a method for automatizing the generation of a new database with electronic structure results for a large number $(22,000)$ of inorganic compounds is presented. The necessary structural information for the $a b$ initio calculations is extracted from the inorganic crystal structure database (ICSD) [8]. The electronic structure results are generated within the local density approximation (LDA) of density functional theory (DFT) in combination with a highly accurate full potential linear muffin-tin orbital (FP-LMTO) method [9].

We describe how data mining algorithms can be applied to the database when searching for any particular class of potentially new advanced materials. This may involve semiconductors with tailored band gaps for solar cells and light harvesting, i.e. materials with desired optical properties, and magnetic compounds for energy conversion or magnetocaloric applications. To demonstrate in detail the power of data mining algorithms with automatic electronic structure calculations we also give a full account of the search and identification of 136 novel compounds with potential 
use as radiation detector materials. In addition, we prove a high success rate of the algorithm by an un-biased identification of several known, successful cerium activated materials.

Radiation detection systems are generally used in areas such as biomedical imaging, nuclear security, nuclear non-proliferation and treaty verification, and in industry. The limiting factors for the performance of these systems are found within the detector material, and improvements are desired in properties like energy resolution for isotope identification in nuclear security, temporal resolution in biomedical imaging, or simply effective detection in small sized systems.

Standard simulations involve to a large extent manual work, where input data files must be generated. We have circumvented this time consuming step by a fully automatic method, where all data files are computer generated after certain materials specific criteria. In addition we have designed a software system which, once all necessary input files have been generated, carries out the simulation automatically (optimization of parameters, truncation criteria, decision-making, etc.). It should also be noted that the algorithm employed has to undertake several steps of learning, in order to decide on a proper set of parameters. For instance, it was found that the definition of the base geometry and basis set used in these calculations [9] needed to be updated after several trial calculations, in order to ensure accuracy of the electronic structure and total energy of the material. Hence all steps of the simulations of this work have been made by artificial intelligence and high performance computation.

The algorithm which executes first principles calculations, with general rules for the computational details as described in Appendix 1, have been applied to some 22,000 compounds from the ICSD database, and the results of these calculations are available on the web site of Ref. [1]. There are a number of electronic structure databases available on the web, e.g. [10-13], however all contain at least two orders of magnitude smaller number of entries than published here, and in addition these studies have been done with different focus. The web-based databases all complement each other however. It should be noted that the crystallographic data from the ICSD originates from different experimental settings, with small variations, giving rise to slightly different electronic structure results and that several entries in ICSD must be disregarded because at least one site has non-trivial occupancy. The control files for our calculations are available upon request.

The crystallographic data needed to construct the control files involves information about the cell geometry, bravais lattice, and the coordinates for each atom and space group. This information is available from the ICSD database [8] in, for example, the CIF (crystallographic information file) format. With access to the CIF files the coordinates can then be unfolded and transformed to the minimal bravais lattice[14]. Our approach can make use of any electronic structure method and can be applied to any compilation of structural geometries, even hypothetical ones which have not yet been identified.

For each entry in Ref. [1] the electronic structure results are presented as figures illustrating band structure, density of states (DOS), partial DOS, and charge density contour maps; furthermore, properties like density, total energy, Fermi energy and band gap (if available) are also listed. Note that the density is calculated using the experimental lattice parameters. Optimizing the lattice parameters, i.e. calculating the bulkmodulus, as well as performing spin polarized calculations will be subjects of future work.

We now proceed with a detailed example on how mining algorithms on the electronic structure information in Ref. [1] may be used for identifying novel scintillator materials. The general philosophy of the mining algorithm is to compare specific electronic structure related properties of a larger set of compounds (i.e. the data in Ref. [1]) to a peer group, which is known to have desired properties connected to a certain functionality of the material. We focus here on suitable candidates for nuclear radiation detector materials, and have chosen two sub-groups of materials: (1) cerium activated scintillating materials, and (2) activated semiconductor materials, e.g. Ga doped $\mathrm{ZnO}$ ( $\mathrm{ZnO}: \mathrm{Ga}$ ) [15]. In identifying principles of data mining for these materials, we consider experimental information regarding characteristic electronic properties for known cerium materials, that show $5 \mathrm{~d}$ to $4 \mathrm{f}$ luminescence, as well as known semiconductor materials which have been found to have encouraging materials properties. The data mining results in 136 candidate materials proposed for further investigation.

A first desirable property for the materials of interest for this study is high detection probability in small sized units, which is associated to the number of available electrons per unit volume. A high density and high atomic number $(Z)$ are therefore desired [16]. Moreover, a short attenuation length is needed and it is also advantageous that photons scatter mainly through the photoelectric channel. These two properties can be characterized with the photoelectric attenuation length (PAL). PAL is the ratio between the calculated attenuation length $\left(\lambda=\mathrm{FW} /\left(\rho \cdot\left[\sigma_{\mathrm{pe}}+\sigma_{\mathrm{C}}\right]\right)\right.$ of the incoming radiation in the material and the calculated fraction between the photoelectric $\left(\sigma_{\mathrm{pe}}\right)$ to Compton scattering $\left(\sigma_{\mathrm{C}}\right)$ cross-sections (or rather, the ratio $\sigma_{\mathrm{pe}} /\left[\sigma_{\mathrm{pe}}+\sigma_{\mathrm{C}}\right]$ ) at some energy, e.g. $511 \mathrm{keV}$, which is the energy scale relevant for positron emission tomography (PET)[16,17]. FW is the formula weight and $\rho$ is the calculated density of the material. The atomic masses and photoelectric- and Compton scattering cross-sections are measured, element specific entities and are listed in Appendix 1. PAL summarizes attenuation length and the efficiency of the photoelectric scattering channel and the lower the PAL value is, the higher is the chance that an incoming $\gamma$-ray is absorbed in the material after a short distance by the photoelectric effect, which makes the material more relevant to our study.

We show in Fig. 1 the distribution and cumulative sums of materials densities and the PALs. A high density requirement is imposed as $\rho>6.5 \mathrm{~g} / \mathrm{cm}^{3}$, and we find 4602 materials satisfying this criterion. As an upper limit for the PAL, the value of a well-known detector material is used, i.e. $\mathrm{Tl}$ doped $\mathrm{NaI}$ with $\mathrm{PAL}_{\mathrm{NaI}: \mathrm{Tl}}=17 \mathrm{~cm}$. This limit is satisfied for about $87 \%$ of the materials also satisfying the high density condition and the selection is reduced to 3983 entries.

We are now left with some four thousand compounds which according to the density and PAL criteria might be suitable detector materials. The synthesis and testing of thousands of candidate compounds is clearly not realistic, nor is it feasible with standard, manually controlled computational methods to go through such a large body of potential materials, to try to identify successful compounds. Hence, more efficient methods are needed, where efficient algorithms for calculating the electronic structure must be combined with data mining techniques. Using a peer group of materials (discussed below) the data mining algorithms can learn selection rules related to electronic structure properties as given by the band structure or the density of states. We will here use the LDA bandgap $\left(E_{\mathrm{g}}\right)$, the width of the highest valence band (vbw), the width of the lowest conduction band (cbw), the width of the highest occupying electron in the valence band (dEe), and the width of the lowest available state in the conduction band (dEh) to further narrow down the list of candidate materials. The definitions of these properties are shown in Fig. 2. It should be noted that the parameter vbw measures how delocalized the highest energy band of the valence states is. In the same way cbw measures the degree of delocalization of the lowest band amongst the conduction band states. The remaining two parameters, $\mathrm{dEe}$ and $\mathrm{dEh}$, give related information, and stand in direct proportion to the effective mass of the highest electron state and the lowest hole state, respectively. As a matter of fact our mining algorithm could have made use of effec- 

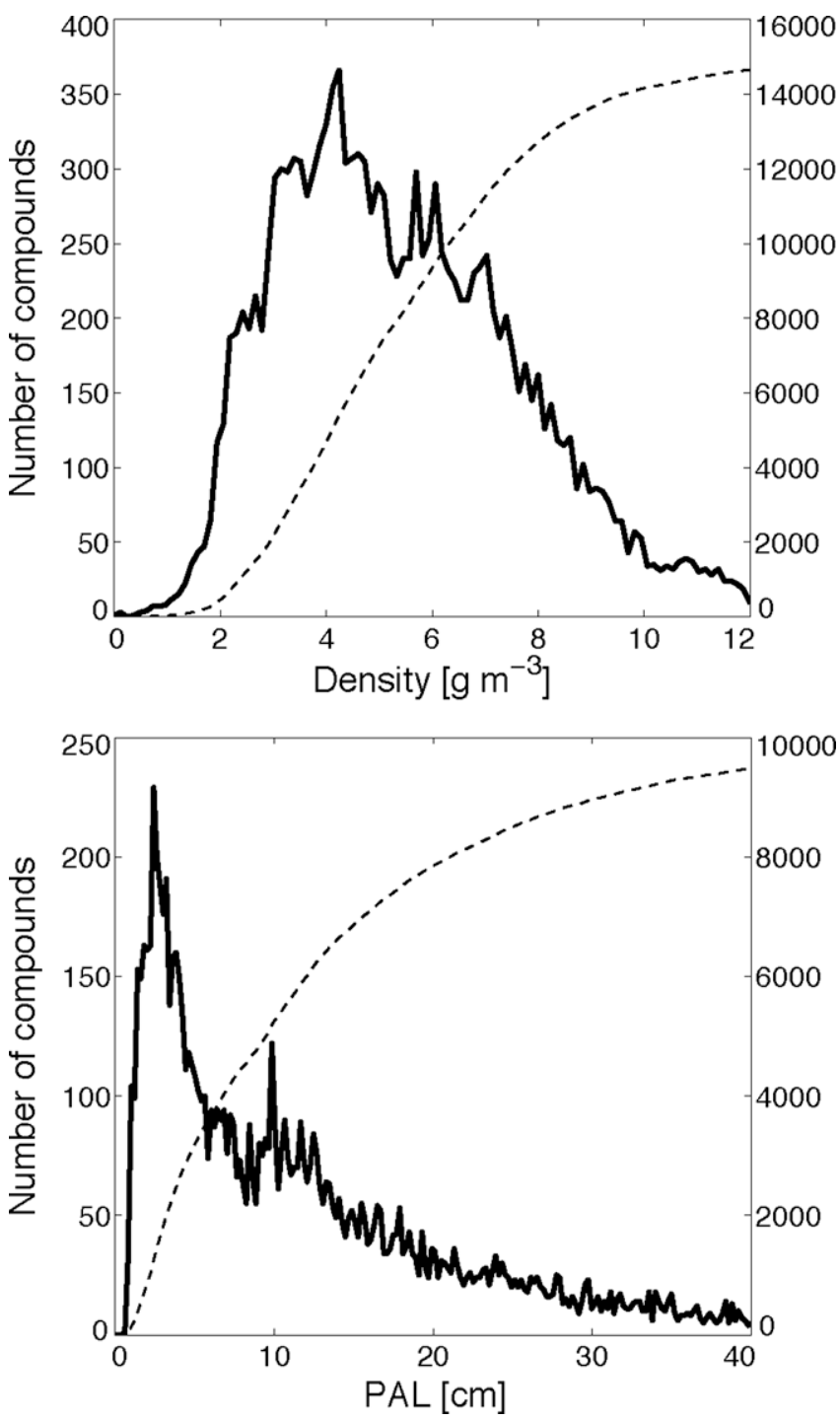

Fig. 1. Profiles for the density (upper graph) and PAL (lower graph) distributions in energy (full line, scale is to the left of the figures) and their cumulative sum (dashed line, scale is to the right of the figures).

tive electron and hole masses, instead of dEe and dEh, without any change in the result of identified materials. When considering the bandgaps a distinction is made between a direct and an in-direct gap material, depending on whether or not the highest energy in the valence band is found at the same point in reciprocal space as the lowest energy in the conduction bands.

The remaining step in the mining algorithm is to make a comparison of a profile of a selected property, e.g. the valence bandand conduction band-width (vbw and cbw, respectively), for the approximately compounds in our database which satisfy the density and PAL criteria, with the corresponding profile for a peer group of materials. This peer group must, of course, have desired properties for the specific functionality desired in the study in question. For semiconducting materials the peer group is composed of well-known materials from Ref. [18].

The profiles of vbw and cbw are shown in Fig. 3. In the case of semiconducting materials for use as scintillators, the mining algorithm concludes from the peer group that the vbw value should be greater than $0.4 \mathrm{eV}$. Analogously, cbw must be greater than $0.9 \mathrm{eV}$. Fig. 4 shows the distributions of dEe and dEh, respectively. From the profile of the peer group of semiconductors, the lower limit

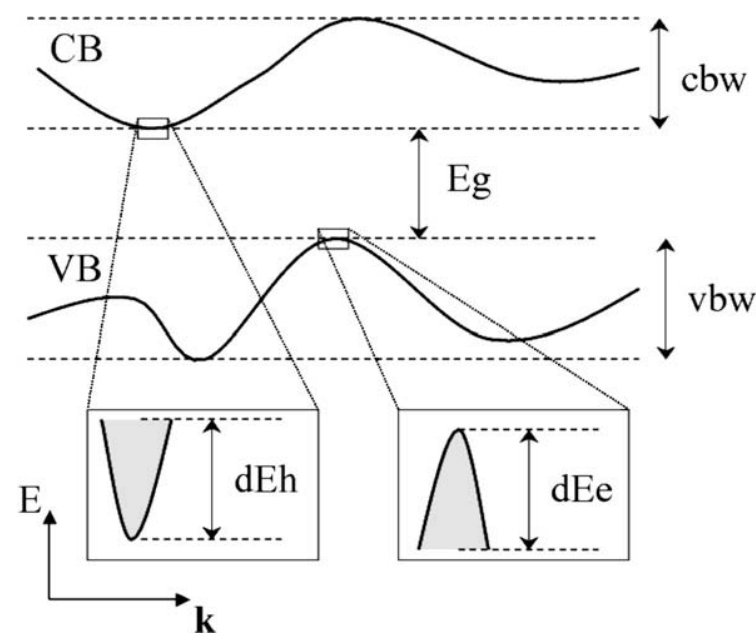

Fig. 2. Illustration of band widths and dispersion relations used in the mining algorithms. Because the values for the lowest of $\mathrm{CB}$ and the highest of VB occur at different positions in reciprocal space, an indirect band gap $\left(E_{\mathrm{g}}\right)$ is shown. By integrating the total density of states around the Fermi level the width of the last occupied electron ( $\mathrm{dEe}$ ) and the width of the first empty state containing one electron (dEh) are found. vbw and cbw represent the width of the valence and conduction band, respectively.

for the $\mathrm{dEe}$ rule is set to $0.02 \mathrm{eV}$. Analogously the lower limit for the dEh rule is set to $0.03 \mathrm{eV}$.

For cerium activated scintillating materials a more complex process is known to take place, and for this reason somewhat different mining rules are used. The scintillating process can be thought to occur as follows; a tri-valent cerium atom captures a hole and goes to the tetra-valent state $\left(\mathrm{Ce}^{3+}+h^{+} \rightarrow \mathrm{Ce}^{4+}\right)$. A subsequent capture of an electron takes the tetra-valent cerium atom to an excited tri-valent state $\left(\mathrm{Ce}^{4+}+e^{-} \rightarrow\left(\mathrm{Ce}^{3+}\right)^{*}\right)$. The process can be thought of as an excitation of the Ce 4 f-electron into the Ce $5 \mathrm{~d}$ state. The band gap of the host material must be large enough to properly accommodate the Ce $4 \mathrm{f}$ and $5 \mathrm{~d}$ states [19]. Finally, the excited state of the tri-valent $\mathrm{Ce}$ atom relaxes to the ground state $\left(\left(\mathrm{Ce}^{3+}\right)^{*} \rightarrow \mathrm{Ce}^{3+}+h v\right)$, with the emission of a photon ( $\left.h v\right)$, ideally around $3 \mathrm{eV}$, which can be detected with conventional photo-electronics. To properly accommodate the Ce $4 \mathrm{f}$ and $5 \mathrm{~d}$ states a large band gap, $>3 \mathrm{eV}$, for the host material is required, and as we will see, this is an important parameter for identifying Ce based scintillator materials. It turns out that the mining rules dEe and dEh are not significant for these materials, and have hence not been used. For this class of systems our peer group is composed of compounds published by Dorenbos in Ref. [20].

Before describing the details of the analysis of band gap properties, we note that first principles calculations normally do not reproduce band gaps with great accuracy, whereas the presence of a gap is with very few exceptions always reproduced by such calculations. By now it is well established that the type of theory presented here results in a band gap which is approximately $50 \%$ of the measured one. Hence it is quite possible to use the calculated band gap as a screening parameter, as long as one makes use of calculated gaps both for the peer group and the group of compounds one performs the data mining for. Fig. 5 shows the band gap profiles for all compounds with a calculated LDA band gap in Ref. [1] (thick full line), for peer groups of Ce doped materials showing cerium $5 \mathrm{~d} \rightarrow 4 \mathrm{f}$ emission (thin full line), semiconducting materials (dashed line), and additionally a profile where Ce doped materials which also contain sulfur is shown (thin full line with circle markers). The reason for introducing the latter profile is that a detailed analysis of the materials listed in Ref. [20] shows that host materials containing sulfur allow cerium $5 \mathrm{~d} \rightarrow 4 \mathrm{f}$ 

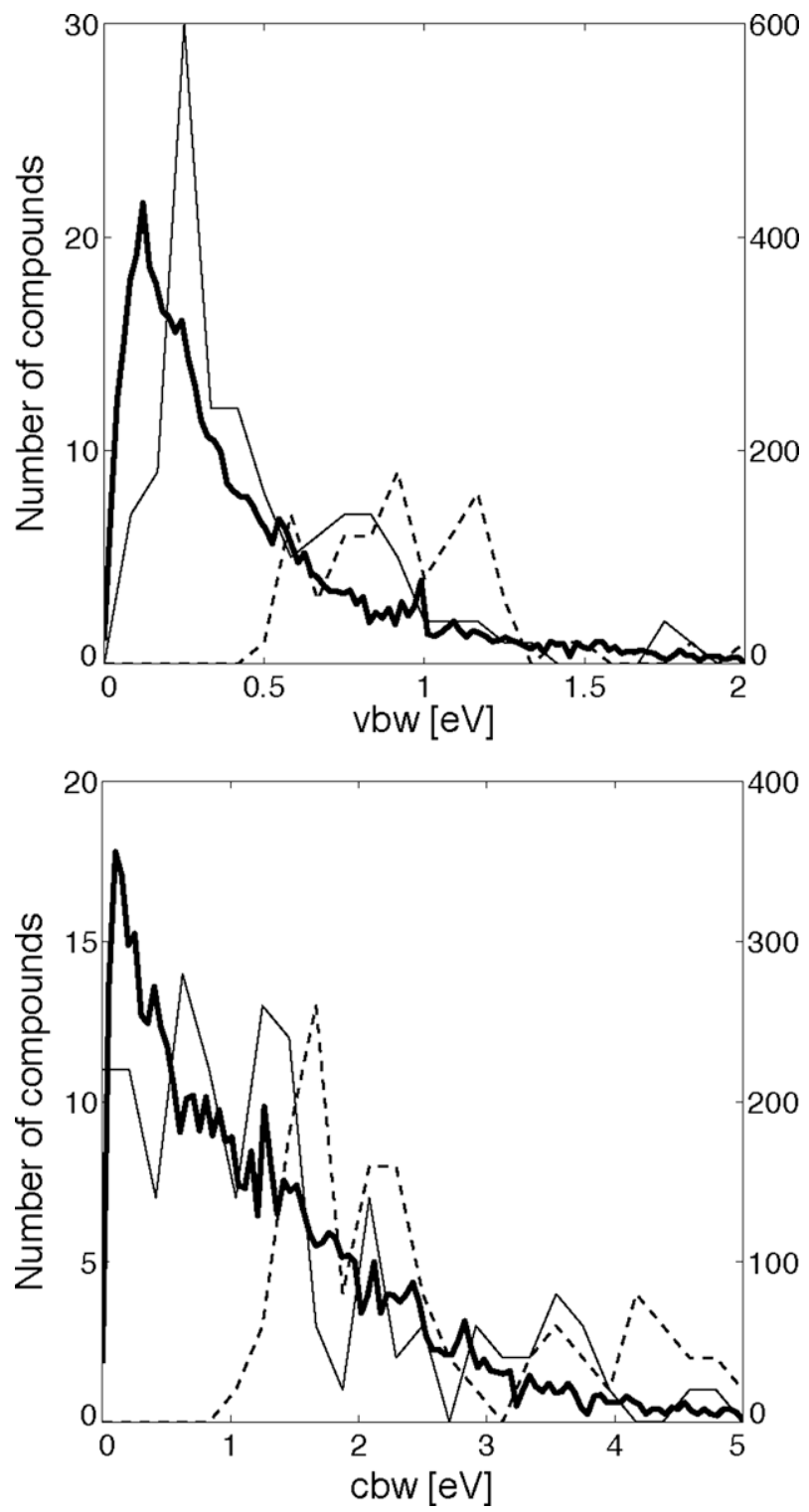

Fig. 3. Profiles for the vbw (upper graph) and cbw (lower graph) distributions in energy. The thick full line shows the distribution for all compounds in Ref. [1] (the scale is on the right of each plot). The thin full line and the dashed line show the profiles for cerium- and semiconductor materials, respectively, defining the peer groups (the scale is on the left of each plot).

emission even though the band gap is smaller compared to Ce materials without sulphur. Therefore the LDA band gap mining rule sets the lower limit of $3 \mathrm{eV}$ for Ce activated host compounds, provided that this number is relaxed down to $1 \mathrm{eV}$ if the material contains sulfur. In addition a band gap below $4 \mathrm{eV}$ is, as shown in Fig. 5 , relevant for semiconductor detector materials. For these systems we also imposed a lower limit of the band gap to $0.4 \mathrm{eV}$, since then thermal noise of the detector is reduced.

The mining algorithm defined for activated semiconducting scintillators is now applied to all materials of Ref. [1] which pass though the PAL and density criterion, and we have been able to identify 66 candidate semiconducting materials. Table 2.1 in Appendix 2 shows how the number of candidate compounds are reduced as the mining algorithm progresses. We see that the incorporation of electronic structure related information in the data mining greatly reduces the number of candidate materials. The requirement of a direct band gap with a width in the range of
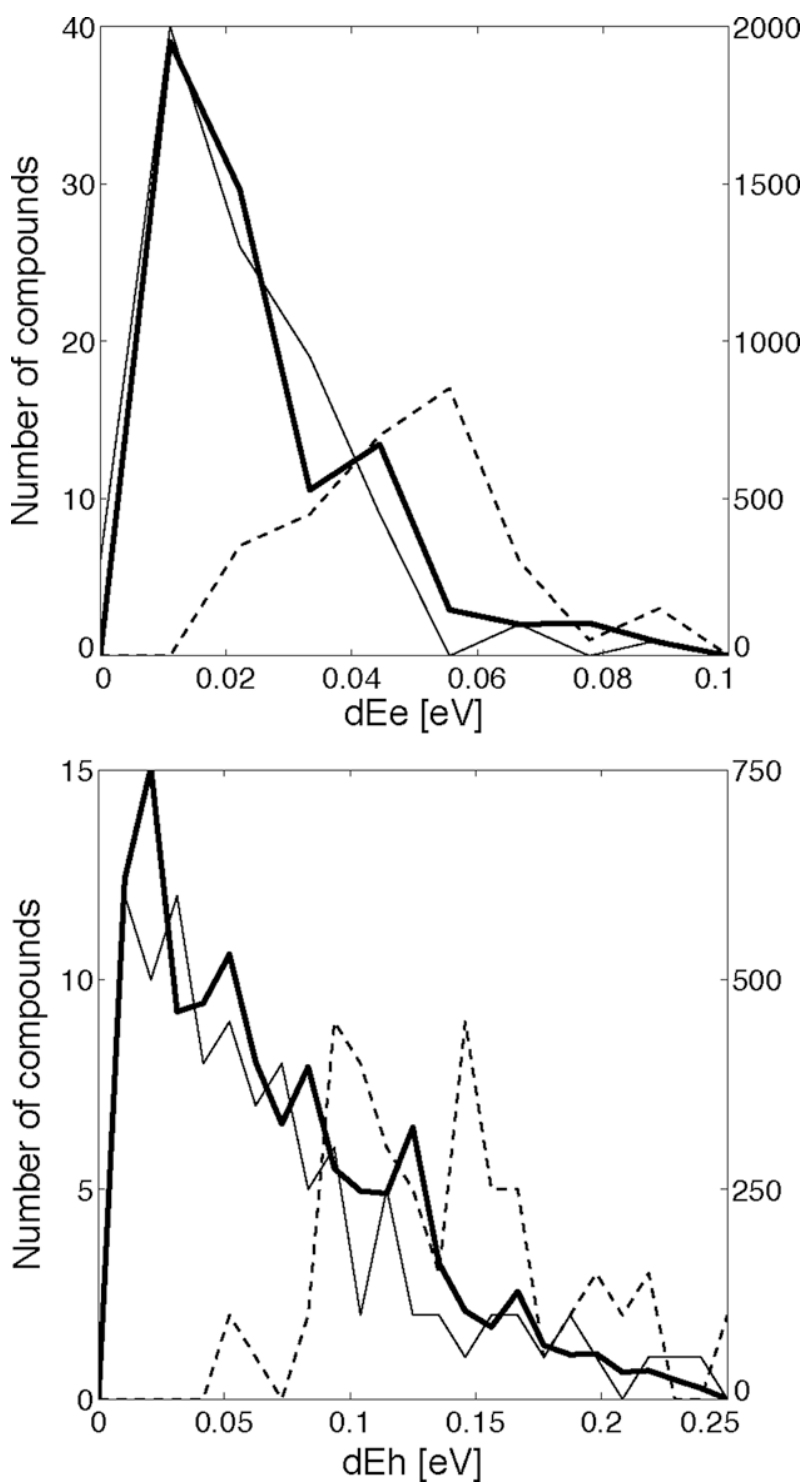

Fig. 4. Profiles for the dEe (upper graph) and dEh (lower graph) distribution in energy. The thick full line shows the distribution for all compounds in Ref. [1] (the scale is on the right of each plot). The thin full line and the dashed line show the profiles for cerium- and semiconductor materials, respectively, defining the peer groups (the scale is on the left of each plot).

$0.4-4 \mathrm{eV}$, rules out most of the materials in Ref. [1], resulting in 195 compounds.

Activated semiconductor scintillators represent a very new and novel class of materials and it remains to be seen if these ultra-fast detector materials can be made highly luminous. Among the currently best ultra-fast activated semiconductors one finds $\mathrm{CuI}, \mathrm{ZnO}$ and CdS [15]. For these systems the electronic bandgap is direct and wide, and in addition cbw is large. The list of predicted materials in Table 3.1 of Appendix 3 have similar bandgaps and values of cbw as these known compounds. However, it should be noted that in the group of CuI, $\mathrm{ZnO}$ and $\mathrm{CdS}$, only CuI is found in Table 3.1 of Appendix 3, because of the very stringent set of criteria imposed in the data mining procedure (in particular, it is the requirement of a high materials density which excludes $\mathrm{ZnO}$ and $\mathrm{CdS}$ from our list). These criteria are designed to substantially improve the currently used materials in scintillator applications. Hence the predicted list of materials have potential to be substantially better than what is used in current technology. We end the discussion 


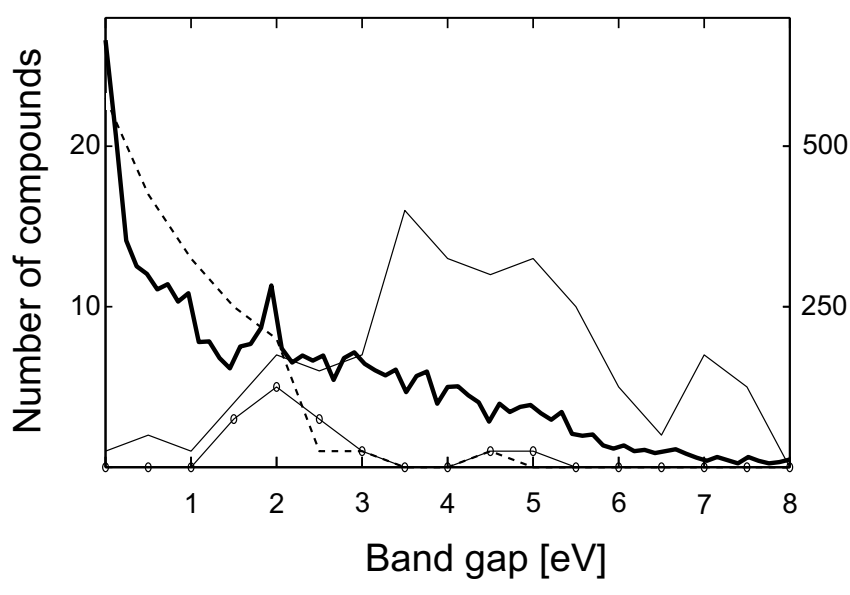

Fig. 5. Profile for the LDA bandgap distribution for all compounds in Ref. [1] (thick full line, the scale is on the right of the figure). Most known cerium activated materials that emit light have an LDA band gap larger than $3 \mathrm{eV}$ (thin full line, scale is to the left of the figure). The thin full line with circle markers show that cerium activated materials where the host contain sulphur can emit light even though the bandgap is small (scale is to the left of the figure). Semiconducting materials from the peer group are shown as a dashed line (scale is to the left of the figure).

of semiconducting scintillators with a short analysis of the crystal chemistry of the identified materials. First we note that space group 129 (tetragonal) and 62 (orthorhombic) are the most common crystal structures found in Table 3.1 of Appendix 3, and that materials with space group 141 (tetragonal), 164 (trigonal) and 225 (fcc) are also rather frequent. Secondly, we note that oxides constitute over $50 \%$ of these materials. We also observe that ionic bonds are present is almost all the materials listed in Table 3.1 (as well as in Table 3.2) of Appendix 3. This is clearly a significant result, which is worthwhile to pursue experimentally, and is a unique feature of our study, since it would be difficult to draw this conclusion with any other technique.

Applying the appropriate mining algorithm for $\mathrm{Ce}$ activated compounds to all materials of Ref. [1] identifies some 70 candidate materials. We note again that the rules learned by the mining algorithm are optimized to identify new materials with superior properties compared to known systems. Table 2.2 in Appendix 2 shows how the number of candidate compounds is reduced as the data mining progresses, and it is clear that the band gap rule stands out as the most efficient. The resulting list of compounds identified as potential hosts for $\mathrm{Ce}$ (Ce activated scintillator materials) are given in Table 3.2 of Appendix 3. For cerium activation, compounds containing Gd, Lu, Y, La and Sc are known to often be efficient scintillators, the reason being that these elements do not introduce electron/hole traps and therefore allow efficient energy transfer to the cerium dopant. Hence, it is gratifying that among the materials in Table 3.2 of Appendix 3, many are indeed rare-earth (RE) based. The quantum efficiency of the cerium $5 \mathrm{~d}$ to $4 \mathrm{f}$ transition is largely dictated by the chemical bonding between the cerium and host atoms, a property which is ideal to investigate with electronic structure methods. The fact that the crystal structure as well as type of host cation are important parameters is reflected in that most useful cerium activated compounds today are orthosilicates, aluminates, phosphates or simple metal-halides. We note that several orthosilicates, aluminates, phosphates or simple metal-halides are predicted in Table 3.2 of Appendix 3.

As regards crystal structure we note that space group 62 constitutes a large group of Ce doped compounds (this space group was also prevalent for the semiconducting scintillators). Space group 14 (monoclinic) and 225 (fcc) are also common in our Table of Ce doped scintillators. Again, and as noted above, the presence of ionic compounds is clear from this table.
Table 1.1

Definition of atomic configurations including atomic number ( $Z$ ), symbol (atom), core- and valence electron configuration

\begin{tabular}{|c|c|c|c|c|c|c|}
\hline$Z$ & Atom & Core & Valence & Atomic mass & $\sigma_{\mathrm{pe}}$ & $\sigma_{\mathrm{C}}$ \\
\hline 1 & $\mathrm{H}$ & & $1 \mathrm{~s}^{1}$ & 1.01 & $8.79 e-09$ & 0.29 \\
\hline 2 & $\mathrm{He}$ & & $1 s^{2}$ & 4.00 & $2.70 e-07$ & 0.57 \\
\hline 3 & $\mathrm{Li}$ & {$[\mathrm{He}]$} & $2 s^{1}$ & 6.94 & $2.62 \mathrm{e}-06$ & 0.86 \\
\hline 4 & $\mathrm{Be}$ & {$[\mathrm{He}]$} & $2 s^{2}$ & 9.01 & $1.33 e-05$ & 1.15 \\
\hline 5 & B & {$[\mathrm{He}]$} & $2 s^{2} 2 p^{1}$ & 10.81 & $4.59 \mathrm{e}-05$ & 1.43 \\
\hline 6 & $\mathrm{C}$ & {$[\mathrm{He}]$} & $2 s^{2} 2 p^{2}$ & 12.01 & $1.22 \mathrm{e}-04$ & 1.72 \\
\hline 7 & $\mathrm{~N}$ & {$[\mathrm{He}]$} & $2 \mathrm{~s}^{2} 2 \mathrm{p}^{3}$ & 14.01 & $2.75 e-04$ & 2.00 \\
\hline 8 & 0 & [He] & $2 s^{2} 2 p^{4}$ & 16.00 & $5.51 \mathrm{e}-04$ & 2.29 \\
\hline 9 & $\mathrm{~F}$ & {$[\mathrm{He}]$} & $2 s^{2} 2 p^{5}$ & 19.00 & $9.85 e-04$ & 2.58 \\
\hline 10 & $\mathrm{Ne}$ & {$[\mathrm{He}]$} & $2 s^{2} 2 p^{6}$ & 20.18 & $1.69 \mathrm{e}-03$ & 2.86 \\
\hline 11 & $\mathrm{Na}$ & {$[\mathrm{Ne}]$} & $3 s^{1}$ & 22.99 & $2.62 \mathrm{e}-03$ & 3.15 \\
\hline 12 & $\mathrm{Mg}$ & {$[\mathrm{Ne}]$} & $3 s^{2}$ & 24.30 & $3.97 e-03$ & 3.43 \\
\hline 13 & $\mathrm{Al}$ & {$[\mathrm{Ne}]$} & $3 s^{2} 3 p^{1}$ & 26.98 & $6.10 e-03$ & 3.72 \\
\hline 14 & $\mathrm{Si}$ & {$[\mathrm{Ne}]$} & $3 s^{2} 3 p^{2}$ & 28.09 & $8.46 e-03$ & 4.00 \\
\hline 15 & $\mathrm{P}$ & {$[\mathrm{Ne}]$} & $3 s^{2} 3 p^{3}$ & 30.97 & $1.18 \mathrm{e}-02$ & 4.29 \\
\hline 16 & $\mathrm{~S}$ & {$[\mathrm{Ne}]$} & $3 s^{2} 3 p^{4}$ & 32.07 & $1.69 \mathrm{e}-02$ & 4.57 \\
\hline 17 & $\mathrm{Cl}$ & {$[\mathrm{Ne}]$} & $3 s^{2} 3 p^{5}$ & 35.45 & $2.19 \mathrm{e}-02$ & 4.86 \\
\hline 18 & $\mathrm{Ar}$ & {$[\mathrm{Ne}]$} & $3 s^{2} 3 p^{6}$ & 39.95 & $2.87 e-02$ & 5.14 \\
\hline 19 & $\mathrm{~K}$ & {$[\mathrm{Ne}]$} & $3 s^{2} 3 p^{6} 4 s^{1}$ & 39.10 & $3.68 \mathrm{e}-02$ & 5.43 \\
\hline 20 & $\mathrm{Ca}$ & {$[\mathrm{Ne}]$} & $3 s^{2} 3 p^{6} 4 s^{2}$ & 40.08 & $4.91 \mathrm{e}-02$ & 5.71 \\
\hline 21 & Sc & {$[\mathrm{Ne}]$} & $3 s^{2} 3 p^{6} 3 d^{1} 4 s^{2}$ & 44.96 & $5.94 \mathrm{e}-02$ & 5.99 \\
\hline 22 & $\mathrm{Ti}$ & {$[\mathrm{Ne}]$} & $3 s^{2} 3 p^{6} 3 d^{2} 4 s^{2}$ & 47.88 & $7.74 \mathrm{e}-02$ & 6.28 \\
\hline 23 & $\mathrm{~V}$ & {$[\mathrm{Ne}]$} & $3 s^{2} 3 p^{6} 3 d^{3} 4 s^{2}$ & 50.94 & $9.47 e-02$ & 6.56 \\
\hline 24 & $\mathrm{Cr}$ & {$[\mathrm{Ne}]$} & $3 s^{2} 3 p^{6} 3 d^{5} 4 s^{1}$ & 52.00 & $1.16 \mathrm{e}-01$ & 6.84 \\
\hline 25 & Mn & {$[\mathrm{Ne}]$} & $3 s^{2} 3 p^{6} 3 d^{5} 4 s^{2}$ & 54.94 & $1.40 \mathrm{e}-01$ & 7.13 \\
\hline 26 & $\mathrm{Fe}$ & {$[\mathrm{Ne}]$} & $3 s^{2} 3 p^{6} 3 d^{6} 4 s^{2}$ & 55.85 & $1.59 \mathrm{e}-01$ & 7.41 \\
\hline 27 & Co & {$[\mathrm{Ne}]$} & $3 s^{2} 3 p^{6} 3 d^{7} 4 s^{2}$ & 58.93 & $1.94 \mathrm{e}-01$ & 7.69 \\
\hline 28 & $\mathrm{Ni}$ & {$[\mathrm{Ar}]$} & $3 d^{8} 4 s^{2}$ & 58.69 & $2.21 \mathrm{e}-01$ & 7.98 \\
\hline 29 & $\mathrm{Cu}$ & {$[\mathrm{Ar}]$} & $3 d^{10} 4 s^{1}$ & 63.55 & $2.65 e-01$ & 8.26 \\
\hline 30 & $\mathrm{Zn}$ & {$[\mathrm{Ar}]$} & $3 d^{10} 4 s^{2}$ & 65.39 & $3.10 \mathrm{e}-01$ & 8.54 \\
\hline 31 & $\mathrm{Ga}$ & {$[\mathrm{Ar}]$} & $3 d^{10} 4 s^{2} 4 p^{1}$ & 69.72 & $3.56 e-01$ & 8.82 \\
\hline 32 & $\mathrm{Ge}$ & {$[\mathrm{Ar}]$} & $3 d^{10} 4 s^{2} 4 p^{2}$ & 72.61 & $4.14 \mathrm{e}-01$ & 9.11 \\
\hline 33 & As & {$[\mathrm{Ar}]$} & $3 d^{10} 4 s^{2} 4 p^{3}$ & 74.92 & $4.68 \mathrm{e}-01$ & 9.39 \\
\hline 34 & $\mathrm{Se}$ & {$[\mathrm{Ar}]$} & $3 d^{10} 4 s^{2} 4 p^{4}$ & 78.96 & $5.49 \mathrm{e}-01$ & 9.67 \\
\hline 35 & $\mathrm{Br}$ & {$[\mathrm{Ar}]$} & $3 d^{10} 4 s^{2} 4 p^{5}$ & 79.90 & $6.24 \mathrm{e}-01$ & 9.95 \\
\hline 36 & $\mathrm{Kr}$ & {$[\mathrm{Ar}]$} & $3 d^{10} 4 s^{2} 4 p^{6}$ & 83.80 & $7.09 \mathrm{e}-01$ & 10.24 \\
\hline 37 & $\mathrm{Rb}$ & {$[\mathrm{Ar}] 3 \mathrm{~d}^{10}$} & $4 s^{2} 4 p^{6} 5 s^{1}$ & 85.47 & $7.98 \mathrm{e}-01$ & 10.52 \\
\hline 38 & $\mathrm{Sr}$ & {$[\mathrm{Ar}] 3 \mathrm{~d}^{10}$} & $4 s^{2} 4 p^{6} 5 s^{2}$ & 87.62 & $9.16 e-01$ & 10.79 \\
\hline 39 & $\mathrm{Y}$ & {$[\mathrm{Ar}] 3 \mathrm{~d}^{10}$} & $4 s^{2} 4 p^{6} 4 d^{1} 5 s^{2}$ & 88.91 & $1.02 \mathrm{e}+00$ & 11.08 \\
\hline 40 & $\mathrm{Zr}$ & {$[\mathrm{Ar}] 3 \mathrm{~d}^{10}$} & $4 s^{2} 4 p^{6} 4 d^{2} 5 s^{2}$ & 91.22 & $1.10 \mathrm{e}+00$ & 11.36 \\
\hline 41 & $\mathrm{Nb}$ & {$[\mathrm{Ar}] 3 \mathrm{~d}^{10}$} & $4 s^{2} 4 p^{6} 4 d^{4} 5 s^{1}$ & 92.91 & $1.27 e+00$ & 11.64 \\
\hline 42 & Mo & {$[\mathrm{Ar}] 3 \mathrm{~d}^{10}$} & $4 s^{2} 4 p^{6} 4 d^{5} 5 s^{1}$ & 95.94 & $1.49 e+00$ & 11.92 \\
\hline 43 & Tc & {$[\mathrm{Ar}] 3 \mathrm{~d}^{10}$} & $4 s^{2} 4 p^{6} 4 d^{6} 5 s^{1}$ & 98.00 & $1.57 e+00$ & 12.20 \\
\hline 44 & $\mathrm{Ru}$ & {$[\mathrm{Ar}] 3 \mathrm{~d}^{10}$} & $4 s^{2} 4 p^{6} 4 d^{7} 5 s^{1}$ & 101.07 & $1.74 \mathrm{e}+00$ & 12.48 \\
\hline 45 & $\mathrm{Rh}$ & {$[\mathrm{Kr}]$} & $4 d^{8} 5 s^{1}$ & 102.91 & $1.92 e+00$ & 12.76 \\
\hline 46 & Pd & {$[\mathrm{Kr}]$} & $4 d^{10}$ & 106.42 & $2.15 e+00$ & 13.04 \\
\hline 47 & $\mathrm{Ag}$ & {$[\mathrm{Kr}]$} & $4 d^{10} 5 s^{1}$ & 107.87 & $2.36 e+00$ & 13.32 \\
\hline 48 & $\mathrm{Cd}$ & {$[\mathrm{Kr}]$} & $4 d^{10} 5 s^{2}$ & 112.41 & $2.60 e+00$ & 13.60 \\
\hline 49 & In & {$[\mathrm{Kr}]$} & $4 d^{10} 5 s^{2} 5 p^{1}$ & 114.82 & $2.87 e+00$ & 13.88 \\
\hline 50 & Sn & {$[\mathrm{Kr}]$} & $4 d^{10} 5 s^{2} 5 p^{2}$ & 118.71 & $3.06 e+00$ & 14.16 \\
\hline 51 & $\mathrm{Sb}$ & {$[\mathrm{Kr}]$} & $4 d^{10} 5 s^{2} 5 p^{3}$ & 121.75 & $3.30 \mathrm{e}+00$ & 14.44 \\
\hline 52 & $\mathrm{Te}$ & {$[\mathrm{Kr}]$} & $4 d^{10} 5 s^{2} 5 p^{4}$ & 127.60 & $3.66 e+00$ & 14.72 \\
\hline 53 & I & {$[\mathrm{Kr}]$} & $4 d^{10} 5 s^{2} 5 p^{5}$ & 126.90 & $4.06 \mathrm{e}+00$ & 15.00 \\
\hline 54 & $\mathrm{Xe}$ & {$[\mathrm{Kr}]$} & $4 d^{10} 5 s^{2} 5 p^{6}$ & 131.29 & $4.31 \mathrm{e}+00$ & 15.27 \\
\hline 55 & Cs & {$[\mathrm{Kr}] 4 \mathrm{~d}^{10}$} & $5 s^{2} 5 p^{6} 6 s^{1}$ & 132.91 & $4.68 e+00$ & 15.55 \\
\hline 56 & $\mathrm{Ba}$ & {$[\mathrm{Kr}] 4 \mathrm{~d}^{10}$} & $5 s^{2} 5 p^{6} 6 s^{2}$ & 137.33 & $5.03 e+00$ & 15.83 \\
\hline 57 & $\mathrm{La}$ & {$[\mathrm{Kr}] 4 \mathrm{~d}^{10}$} & $5 s^{2} 5 p^{6} 5 d^{1} 6 s^{2}$ & 138.91 & $5.47 e+00$ & 16.11 \\
\hline 58 & $\mathrm{Ce}$ & {$[\mathrm{Kr}] 4 \mathrm{~d}^{10} 4 \mathrm{f}^{2}$} & $5 s^{2} 5 p^{6} 6 s^{2}$ & 140.12 & $5.86 e+00$ & 16.38 \\
\hline 59 & $\operatorname{Pr}$ & {$[\mathrm{Kr}] 4 \mathrm{~d}^{10} 4 \mathrm{f}^{3}$} & $5 s^{2} 5 p^{6} 6 s^{2}$ & 140.91 & $6.41 \mathrm{e}+00$ & 16.66 \\
\hline 60 & $\mathrm{Nd}$ & {$[\mathrm{Kr}] 4 \mathrm{~d}^{10} 4 \mathrm{f}^{4}$} & $5 s^{2} 5 p^{6} 6 s^{2}$ & 144.24 & $6.95 e+00$ & 16.94 \\
\hline 61 & $\mathrm{Pm}$ & {$[\mathrm{Kr}] 4 \mathrm{~d}^{10} 4 \mathrm{f}^{5}$} & $5 s^{2} 5 p^{6} 6 s^{2}$ & 145.00 & $7.43 e+00$ & 17.22 \\
\hline 62 & $\mathrm{Sm}$ & {$[\mathrm{Kr}] 4 \mathrm{~d}^{10} 4 \mathrm{f}^{6}$} & $5 s^{2} 5 p^{6} 6 s^{2}$ & 150.36 & $7.96 e+00$ & 17.50 \\
\hline 63 & $\mathrm{Eu}$ & {$[\mathrm{Kr}] 4 \mathrm{~d}^{10} 4 \mathrm{f}^{7}$} & $5 s^{2} 5 p^{6} 6 s^{2}$ & 151.97 & $8.56 e+00$ & 17.77 \\
\hline 64 & Gd & {$[\mathrm{Kr}] 4 \mathrm{~d}^{10} 4 \mathrm{f}^{7}$} & $5 s^{2} 5 p^{6} 5 d^{1} 6 s^{2}$ & 157.25 & $9.02 e+00$ & 18.05 \\
\hline 65 & $\mathrm{~Tb}$ & {$[\mathrm{Kr}] 4 \mathrm{~d}^{10} 4 \mathrm{f}^{9}$} & $5 s^{2} 5 p^{6} 6 s^{2}$ & 158.93 & $9.78 e+00$ & 18.33 \\
\hline 66 & Dy & {$[\mathrm{Kr}] 4 \mathrm{~d}^{10} 4 \mathrm{f}^{10}$} & $5 s^{2} 5 p^{6} 6 s^{2}$ & 162.50 & $1.05 e+01$ & 18.60 \\
\hline 67 & Ho & {$[\mathrm{Kr}] 4 \mathrm{~d}^{10} 4 \mathrm{f}^{11}$} & $5 s^{2} 5 p^{6} 6 s^{2}$ & 164.93 & $1.11 \mathrm{e}+01$ & 18.88 \\
\hline 68 & $\mathrm{Er}$ & {$[\mathrm{Kr}] 4 \mathrm{~d}^{10} 4 \mathrm{f}^{12}$} & $5 s^{2} 5 p^{6} 6 s^{2}$ & 167.26 & $1.19 e+01$ & 19.16 \\
\hline 69 & $\mathrm{Tm}$ & {$[\mathrm{Kr}] 4 \mathrm{~d}^{10} 4 \mathrm{f}^{13}$} & $5 s^{2} 5 p^{6} 6 s^{2}$ & 168.93 & $1.27 e+01$ & 19.44 \\
\hline 70 & $\mathrm{Yb}$ & {$[\mathrm{Kr}] 4 \mathrm{~d}^{10} 4 \mathrm{f}^{14}$} & $5 s^{2} 5 p^{6} 6 s^{2}$ & 173.04 & $1.37 e+01$ & 19.71 \\
\hline 71 & $\mathrm{Lu}$ & {$[\mathrm{Kr}] 4 \mathrm{~d}^{10} 4 \mathrm{f}^{14}$} & $5 s^{2} 5 p^{6} 5 d^{1} 6 s^{2}$ & 174.97 & $1.44 \mathrm{e}+01$ & 19.98 \\
\hline 72 & $\mathrm{Hf}$ & {$[\mathrm{Xe}] 4 \mathrm{f}^{14}$} & $5 d^{2} 6 s^{2}$ & 178.49 & $1.48 \mathrm{e}+01$ & 20.26 \\
\hline 73 & $\mathrm{Ta}$ & {$[\mathrm{Xe}] 4 \mathrm{f}^{14}$} & $5 d^{3} 6 s^{2}$ & 180.95 & $1.57 e+01$ & 20.54 \\
\hline 74 & W & {$[\mathrm{Xe}] 4 \mathrm{f}^{14}$} & $5 d^{4} 6 s^{2}$ & 183.85 & $\begin{array}{c}1.65 \mathrm{e}+01 \\
\text { inued on nex }\end{array}$ & $\begin{array}{r}20.81 \\
\text { t page) }\end{array}$ \\
\hline
\end{tabular}


Table 1.1 (continued)

\begin{tabular}{lllllll}
\hline$Z$ & Atom & Core & Valence & Atomic mass & $\sigma_{\text {pe }}$ & $\sigma_{\mathrm{c}}$ \\
\hline 75 & $\mathrm{Re}$ & {$[\mathrm{Xe}] 4 \mathrm{f}^{14}$} & $5 \mathrm{~d}^{5} 6 \mathrm{~s}^{2}$ & 186.21 & $1.78 \mathrm{e}+01$ & 21.08 \\
76 & $\mathrm{Os}$ & {$[\mathrm{Xe}] 4 \mathrm{f}^{14}$} & $5 \mathrm{~d}^{6} 6 \mathrm{~s}^{2}$ & 190.20 & $1.94 \mathrm{e}+01$ & 21.36 \\
77 & $\mathrm{Ir}$ & {$[\mathrm{Xe}] 4 \mathrm{f}^{14}$} & $5 \mathrm{~d}^{7} 6 \mathrm{~s}^{2}$ & 192.22 & $2.06 \mathrm{e}+01$ & 21.64 \\
78 & $\mathrm{Pt}$ & {$[\mathrm{Xe}] 4 \mathrm{f}^{14}$} & $5 \mathrm{~d}^{9} 6 \mathrm{~s}^{1}$ & 195.08 & $2.11 \mathrm{e}+01$ & 21.91 \\
79 & $\mathrm{Au}$ & {$[\mathrm{Xe}] 4 \mathrm{f}^{14}$} & $5 \mathrm{~d}^{10} 6 \mathrm{~s}^{1}$ & 196.97 & $2.23 \mathrm{e}+01$ & 22.19 \\
80 & $\mathrm{Hg}$ & {$[\mathrm{Xe}] 4 \mathrm{f}^{14}$} & $5 \mathrm{~d}^{10} 6 \mathrm{~s}^{2}$ & 200.59 & $2.36 \mathrm{e}+01$ & 22.46 \\
81 & $\mathrm{Tl}$ & {$[\mathrm{Xe}] 4 \mathrm{f}^{14}$} & $5 \mathrm{~d}^{10} 6 \mathrm{~s}^{2} 6 \mathrm{p}^{1}$ & 204.38 & $2.56 \mathrm{e}+01$ & 22.73 \\
82 & $\mathrm{~Pb}$ & {$[\mathrm{Xe}] 4 \mathrm{f}^{14}$} & $5 \mathrm{~d}^{10} 6 \mathrm{~s}^{2} 6 \mathrm{p}^{2}$ & 207.20 & $2.65 \mathrm{e}+01$ & 23.01 \\
83 & $\mathrm{Bi}$ & {$[\mathrm{Xe}] 4 \mathrm{f}^{14}$} & $5 \mathrm{~d}^{10} 6 \mathrm{~s}^{2} 6 \mathrm{p}^{3}$ & 208.98 & $2.80 \mathrm{e}+01$ & 23.28 \\
84 & $\mathrm{Po}$ & {$[\mathrm{Xe}] 4 \mathrm{f}^{14}$} & $5 \mathrm{~d}^{10} 6 \mathrm{~s}^{2} 6 \mathrm{p}^{4}$ & 209.00 & $3.00 \mathrm{e}+01$ & 23.55 \\
85 & $\mathrm{At}$ & {$[\mathrm{Xe}] 4 \mathrm{f}^{14}$} & $5 \mathrm{~d}^{10} 6 \mathrm{~s}^{2} 6 \mathrm{p}^{5}$ & 210.00 & $3.15 \mathrm{e}+01$ & 23.82 \\
86 & $\mathrm{Rn}$ & {$[\mathrm{Xe}] 4 \mathrm{f}^{14}$} & $5 \mathrm{~d}^{10} 6 \mathrm{~s}^{2} 6 \mathrm{p}^{6}$ & 222.00 & $3.33 \mathrm{e}+01$ & 24.10 \\
87 & $\mathrm{Fr}$ & {$[\mathrm{Xe}] 4 \mathrm{f}^{14} 5 \mathrm{~d}^{10}$} & $6 \mathrm{~s}^{2} 6 \mathrm{p}^{6} 7 \mathrm{~s}^{1}$ & 223.00 & $3.47 \mathrm{e}+01$ & 24.38 \\
88 & $\mathrm{Ra}$ & {$[\mathrm{Xe}] 4 \mathrm{f}^{14} 5 \mathrm{~d}^{10}$} & $6 \mathrm{~s}^{2} 6 \mathrm{p}^{6} 7 \mathrm{~s}^{2}$ & 226.03 & $3.65 \mathrm{e}+01$ & 24.64 \\
89 & Ac & {$[\mathrm{Xe}] 4 \mathrm{f}^{14} 5 \mathrm{~d}^{10}$} & $6 \mathrm{~s}^{2} 6 \mathrm{p}^{6} 6 \mathrm{~d}^{1} 7 \mathrm{~s}^{2}$ & 227.03 & $3.82 \mathrm{e}+01$ & 24.92 \\
\hline
\end{tabular}

The atomic masses as well as photoelectric- and Compton cross-sections are also listed.

It might be argued that a theoretical prediction of novel materials with improved properties is uncertain, if it is not accompanied by an experimental verification. To work around this argument without doing any real synthesis and measurements it is useful to consider the following. Suppose some of the most successful/ useful cerium activated detector materials, e.g. $\mathrm{LaBr}_{3}, \mathrm{LaCl}_{3}, \mathrm{LaF}_{3}$, $\mathrm{Lu}_{2} \mathrm{SiO}_{5}, \mathrm{Gd}_{2} \mathrm{SiO}_{5}, \mathrm{LuPO}_{4}, \mathrm{YAlO}_{3}$ and $\mathrm{CeF}_{3}$, had never been discovered, would the present method be capable of identifying them? To answer this question we removed the materials listed above from the peer group, thus forcing the mining algorithm to learn from a smaller peer group, to see if our algorithms would identify these well-known compounds. The results of this analysis is indeed very encouraging. Four out of the eight materials are immediately identified $\left(\mathrm{LaF}_{3}, \mathrm{Lu}_{2} \mathrm{SiO}_{5}, \mathrm{Gd}_{2} \mathrm{SiO}_{5}\right.$ and $\left.\mathrm{LuPO}_{4}\right) . \mathrm{LaBr}_{3}$ and $\mathrm{CeF}_{3}$ do not appear in our list, because they have too low density and the compounds $\mathrm{LaCl}_{3}$ and $\mathrm{YAlO}_{3}$ are also excluded since they have too high PAL value. Should the density cut-off be set to $5.0, \mathrm{LaBr}_{3}$ and $\mathrm{CeF}_{3}$ would also have been identified as well as several more interesting compounds, e.g. Ce doped $\mathrm{Y}_{2} \mathrm{Si}_{2} \mathrm{O}_{7}$. If we had used a higher value of the PAL, in the screening process, we would also have included $\mathrm{LaCl}_{3}$ and $\mathrm{YAlO}_{3}$ (as well as several other compounds), but it should be noted that the too high PAL value of these two compounds is known to make them less attractive as scintillator materials, even though they have positive features like low cost and are easily synthesized. The exercise described above shows that our mining algorithm and electronic structure method has the desired accuracy for identifying novel materials with desired properties.

Inspection of Table 3.2 in Appendix 3 reveal several compounds of special interest and $\mathrm{AsLuO}_{4}$ and $\mathrm{ClGdO}$ stand out in this group, especially because the first is isoelectronic to $\mathrm{LuPO}_{4}$ and the latter one is related to the compound BrGdO, which is a known highly luminous phosphor. In fact lanthanide oxyhalides doped with cerium are interesting because also the La and Lu versions are wellknown luminous phosphor materials. We note that the successful materials discussed in the previous paragraph all have large LDA bandgaps and this fact indicates that the following materials also deserve special attention: $\mathrm{AlO}_{3} \mathrm{~Tb}, \mathrm{Al}_{2} \mathrm{Gd}_{2} \mathrm{O}_{7} \mathrm{Sr}, \mathrm{Ba}_{4} \mathrm{O}_{10} \mathrm{Ru}_{3}$ and $\mathrm{O}_{4} \mathrm{SrYb}_{2}$.

The materials predicted here are the sole result of theoretical modeling and are found by using a data mining algorithm which uses material properties of a peer group of already well-known materials. Obviously the method presented here can be employed to identify materials with other properties, for instance novel materials for fuel cell and battery applications, super hard compounds and magnetic nano-devices with taylormade transport properties.

\section{Acknowledgements}

We thank Dr. B. Sanyal, Dr. D. Åberg, and Dr. B. Sadigh for helpful discussions on electronic structure theory, and Dr. M. J. Weber, Dr. S. E. Derenzo, and Dr. W. W. Moses for helpful discussions on radiation detection. This work has been sponsored in part by NNSA/na22; HSARPA; Stiftelsen för internationalisering av högre utbildning och forskning (STINT); Vetenskapsrådet (VR); Kungliga vetenskapsakademin (KVA); SNIC/SNAC and the Göran Gustafsson Stiftelse.

\section{Appendix 1}

Any $a b$ initio method requires initial input data for the atomic species and their relative position in the crystal as well as information about truncation in expansion of wavefunctions, density and potential. The structural data are in this work extracted from the ICSD [8]. Additionally for the FP-LMTO method used here [9] we need to define:

- A muffin-tin radius, $R_{\mathrm{MT}}$, optimized to be the largest value for non-overlapping neighboring spheres. The initial value for $R_{\mathrm{MT}}$ is set to be the ionic radius. The electronic structure calculation is iterated three times and between each iteration $R_{\mathrm{MT}}$ is set to the smallest value for where the potential between each atom pair reaches a maximum.

- An upper limit, $l_{\text {cut }}$, for the expansion of the angular part of the wavefunctions inside the muffin-tin, which we set equal to the highest populated orbital in the valence, plus one (e.g. for spbonded materials we use $\mathrm{s}, \mathrm{p}$ and $\mathrm{d}$ orbitals as basis functions).

- The expansion of density and potential inside the muffin-tin radius is done up to $l_{\text {cut }}=6$.

- The grid for the sampling of the irreducible Brillouin zone and the Fourier mesh for expanding the density and potential in the interstitial are all set inversely proportional to the lengths of the crystal axes and to include all high symmetry points. Hence for smaller cells we make use of a higher number of $k$-points whereas for larger cells we use a smaller number of $k$-points.

- For each atom a selection of which electronic states should be categorized as chemically inert core states, and which are considered to be chemically active valence orbitals must be made. We have here made a conventional choice which is listed in Table 1.1.

A set of programs have been implemented using ANSI C, to perform the complex input file setup to the electronic structure code of Ref. [9]. This includes decision-making such as the optimal muffin-tin radius. The set of programs have been programmed to function exactly as a user would work, when setting up the input files. It is stressed once again that the only information needed as input for this electronic structure database is the nonreducible fractional coordinates, the lattice parameters and the space group for each compound. This information is obtained from ICSD [8].

A similar approach is used to verify the correctness of the calculations. A set of locally implemented programs using ANSI C, perform the same checks as would a user do. The following steps are verified to maximize the likelihood a properly converged solution:

- The structure is confirmed to have realistic nearest neighbor distances and density.

- The muffin-tin spheres are confirmed not to overlap.

- The Fourier grid is verified to be dense enough.

- The core leakage is confirmed to not be more than 0.1 . 
- The matching between density in interstitial region and muffintin region is confirmed to be smooth.

- The self-consistency criterion is full-filled, both with respect to total energy and electron density.

- The number of iterations needed in the self-consistent cycle is verified to be small, preferably less than 20 .

- For a number of cases we have also verified that the projected atomic charges are realistic. Automatic routines for this check is under implementation.

Should any of the above tests fail a flag of caution is raised indicating that the electronic structure solution could be converged to the wrong ground state. It should be noted however, that it is difficult with our approach to avoid converging to a local minimum (instead of a global minimum) in the electronic energy functional, but this problem is equally difficult to avoid with manual calculations. The first principles calculations are made automatic with the aid of $\sim 30$ ANSI $C$ control programs.

\section{Appendix 2}

Table 2.1

Results of the mining algorithm for wide-gap semiconductor materials

\begin{tabular}{llc}
\hline Parameter & Limit & No. remaining \\
\hline & Ref. [1] & 22,283 \\
Density & $>6.5 \mathrm{~g} / \mathrm{cm}^{3}$ & 4602 \\
PAL & $<17 \mathrm{~cm}$ & 3983 \\
Gap type & Direct & 334 \\
Band gap & $0.4<E_{\mathrm{g}}<4 \mathrm{eV}$ & 195 \\
vbw & $>0.4 \mathrm{eV}$ & 121 \\
cbw & $>0.6 \mathrm{eV}$ & 104 \\
dEe & $>0.01 \mathrm{eV}$ & 68 \\
dEh & $>0.03 \mathrm{eV}$ & 66 \\
\hline
\end{tabular}

A final list of 66 compounds is obtained.

a An upper limit of $13.0 \mathrm{~g} / \mathrm{cm}^{3}$ is applied for the density.

Table 2.2

Results of the mining algorithm for host materials with Ce-activation when applied to Ref. [1]

\begin{tabular}{llc}
\hline Parameter & Limit & No. remaining \\
\hline & Ref. [1] & 22,283 \\
Density $^{\mathrm{a}}$ & $>6.5 \mathrm{~g} / \mathrm{cm}^{3}$ & 4602 \\
PAL & $<17 \mathrm{~cm}$ & 3982 \\
Dope site & Yes & 1,825 \\
LDA gap & $>3.0 \mathrm{eV}$ & 64 \\
LDA gap & $1.0<E_{\mathrm{g}}<3.0 \mathrm{eV}$ & 6 \\
vbw & $>0.1 \mathrm{eV}$ & 62 \\
cbw & $>0.2 \mathrm{eV}$ & 60 \\
\hline
\end{tabular}

A final list of 60 compounds is listed, which becomes a list of 70 compounds if cbw and cbw are ignored and the sulphur containing small band gap compounds are included.

a An upper limit of $13.0 \mathrm{~g} / \mathrm{cm}^{3}$ is applied for the density.

b Compounds that pass this test must have a $3+$ site or selected $2+$ site. At least one of the following elements need to be present: $\mathrm{La}, \mathrm{Ce}, \mathrm{Gd}, \mathrm{Y}, \mathrm{Lu}, \mathrm{Sc}, \mathrm{Be}, \mathrm{Mg}, \mathrm{Ca}, \mathrm{Sr}$, $\mathrm{Ba}, \mathrm{Al}, \mathrm{Ga}$, In, Tl, As, Sb, Bi. If Pr, Nd, Pm, Sm, Dy, Ho, Er, Tm, or an element with $Z>83$ is present the compound is excluded.

\section{Appendix 3}

Table 3.1

Semiconducting materials

\begin{tabular}{|c|c|c|c|c|c|c|c|}
\hline Material & Spgrp & $\rho$ & PAL & $E_{\mathrm{g}}$ & Gap type & wbw/cbw & ICSD no. \\
\hline $\mathrm{AgHg}_{2} \mathrm{O}_{4} \mathrm{P}$ & 55 & 8.2 & 2.5 & 1.35 & direct & $0.46 / 1.81$ & 2208 \\
\hline $\mathrm{AgI}_{2} \mathrm{Tl}$ & 140 & 7.1 & 3.7 & 1.14 & direct & $0.46 / 1.77$ & 23159 \\
\hline AgLaOS & 129 & 6.6 & 9.4 & 1.18 & direct & $1.30 / 1.96$ & 15530 \\
\hline $\mathrm{Ag}_{2} \mathrm{HgO}_{2}$ & 96 & 9.3 & 2.8 & 0.51 & direct & $0.43 / 1.35$ & 280333 \\
\hline $\mathrm{Ag}_{2} \mathrm{~S}$ & 14 & 7.3 & 12.0 & 0.57 & direct & $0.61 / 2.07$ & 44507 \\
\hline $\mathrm{Ag}_{3} \mathrm{LiO}_{2}$ & 72 & 7.1 & 11.9 & 0.65 & direct & $0.64 / 1.31$ & 4204 \\
\hline $\mathrm{AlO}_{2} \mathrm{Tl}$ & 166 & 7.3 & 2.3 & 1.59 & direct & $0.65 / 0.70$ & 29010 \\
\hline $\mathrm{AsLuO}_{4}$ & 141 & 6.9 & 5.0 & 3.40 & direct & $0.84 / 1.92$ & 2506 \\
\hline $\mathrm{As}_{2} \mathrm{Eu}_{4} \mathrm{O}$ & 139 & 6.9 & 5.3 & 0.78 & direct & $1.01 / 1.37$ & 1222 \\
\hline $\mathrm{AuBr}$ & 138 & 8.2 & 2.5 & 1.42 & direct & $1.30 / 1.01$ & 200287 \\
\hline $\mathrm{AuBr}$ & 141 & 8.2 & 2.4 & 1.68 & direct & $0.55 / 1.10$ & 200286 \\
\hline $\mathrm{AuCl}$ & 141 & 7.8 & 2.2 & 1.30 & direct & $0.84 / 1.12$ & 6052 \\
\hline AuI & 138 & 8.3 & 2.5 & 1.42 & direct & $1.10 / 0.72$ & 24268 \\
\hline AuLiS & 70 & 7.0 & 2.5 & 1.34 & direct & $0.87 / 1.37$ & 280534 \\
\hline $\mathrm{Au}_{4} \mathrm{~S}_{3} \mathrm{Tl}_{2}$ & 59 & 10.2 & 1.5 & 0.86 & direct & $0.62 / 0.80$ & 51235 \\
\hline $\mathrm{BaO}$ & 129 & 8.2 & 6.1 & 1.84 & direct & $1.36 / 3.81$ & 15301 \\
\hline BaSe & 221 & 6.6 & 9.8 & 1.08 & direct & $3.48 / 6.67$ & 52695 \\
\hline $\mathrm{BiFO}$ & 129 & 9.3 & 1.6 & 2.55 & direct & $1.13 / 1.65$ & 24096 \\
\hline BilO & 129 & 9.7 & 1.9 & 0.70 & direct & $1.49 / 2.78$ & 29145 \\
\hline $\mathrm{BiO}_{4} \mathrm{Sb}$ & 15 & 8.5 & 2.5 & 2.53 & direct & $0.53 / 0.89$ & 75901 \\
\hline $\mathrm{Bi}_{2} \mathrm{O}_{6} \mathrm{Te}$ & 64 & 9.1 & 2.0 & 1.84 & direct & $0.72 / 1.23$ & 6239 \\
\hline $\mathrm{Bi}_{6} \mathrm{Cu}_{2} \mathrm{~Pb}_{2} \mathrm{~S}_{12}$ & 26 & 7.0 & 2.3 & 0.45 & direct & $0.65 / 0.82$ & 95926 \\
\hline $\mathrm{BrFPb}$ & 129 & 7.7 & 2.4 & 2.49 & direct & $1.14 / 1.60$ & 30288 \\
\hline $\mathrm{BrTl}$ & 221 & 7.5 & 2.4 & 1.75 & direct & $1.81 / 4.11$ & 61532 \\
\hline BrTl & 225 & 6.6 & 2.7 & 1.92 & direct & $2.20 / 3.00$ & 61519 \\
\hline $\mathrm{Br}_{4} \mathrm{STl}_{6}$ & 128 & 7.4 & 2.3 & 1.74 & direct & $0.86 / 0.67$ & 40521 \\
\hline $\mathrm{Br}_{6} \mathrm{HgTl}_{4}$ & 128 & 7.0 & 2.7 & 1.81 & direct & $0.60 / 0.82$ & 9325 \\
\hline $\mathrm{CO}_{3} \mathrm{~Pb}$ & 62 & 6.6 & 2.5 & 2.97 & direct & $0.46 / 0.90$ & 36164 \\
\hline $\mathrm{CaHgO}_{2}$ & 166 & 6.5 & 2.9 & 2.42 & direct & $0.41 / 1.72$ & 80717 \\
\hline $\mathrm{CdHgO}_{2}$ & 12 & 9.5 & 2.3 & 0.60 & direct & $0.61 / 2.52$ & 74848 \\
\hline $\mathrm{CdI}_{6} \mathrm{Tl}_{4}$ & 128 & 6.9 & 3.1 & 1.78 & direct & $0.43 / 0.87$ & 60756 \\
\hline $\mathrm{ClFPb}$ & 129 & 7.2 & 2.3 & 3.04 & direct & $1.01 / 1.53$ & 30287 \\
\hline $\mathrm{ClO}_{12} \mathrm{P}_{3} \mathrm{~Pb}_{5}$ & 176 & 7.2 & 2.4 & 2.44 & direct & $0.49 / 0.69$ & 24238 \\
\hline $\mathrm{ClO}_{2} \mathrm{PbSb}$ & 63 & 7.0 & 3.1 & 1.64 & direct & $0.76 / 1.85$ & 86229 \\
\hline $\mathrm{Cl}_{2} \mathrm{Hg}_{7} \mathrm{O}_{3}$ & 57 & 9.6 & 1.6 & 0.60 & direct & $0.64 / 1.42$ & 83225 \\
\hline $\mathrm{Cl}_{4} \mathrm{STl}_{6}$ & 128 & 7.1 & 2.1 & 1.46 & direct & $1.05 / 0.80$ & 35289 \\
\hline $\mathrm{CrHg}_{5} \mathrm{O}_{6}$ & 15 & 8.9 & 1.8 & 0.96 & direct & $0.44 / 0.81$ & 81605 \\
\hline CsI & 221 & 9.0 & 5.5 & 1.54 & direct & $5.34 / 9.04$ & 56524 \\
\hline CuI & 129 & 6.9 & 10.6 & 0.98 & direct & $1.63 / 3.48$ & 78268 \\
\hline $\mathrm{Eu}_{2} \mathrm{O}_{4} \mathrm{Si}$ & 62 & 6.7 & 5.8 & 3.91 & direct & $0.53 / 1.81$ & 1510 \\
\hline FIPb & 129 & 7.4 & 2.6 & 1.50 & direct & $1.10 / 1.44$ & 279599 \\
\hline FInO & 70 & 6.6 & 13.1 & 1.62 & direct & $0.77 / 4.03$ & 2521 \\
\hline FTl & 139 & 8.4 & 1.7 & 1.82 & direct & $2.87 / 5.95$ & 9893 \\
\hline FTl & 28 & 9.0 & 1.6 & 1.37 & direct & $1.12 / 2.14$ & 16112 \\
\hline FTl & 69 & 8.5 & 1.7 & 1.73 & direct & $2.94 / 6.06$ & 30268 \\
\hline $\mathrm{F}_{2} \mathrm{Hg}$ & 225 & 9.3 & 1.8 & 0.41 & direct & $0.50 / 4.25$ & 33614 \\
\hline $\mathrm{F}_{7} \mathrm{SiTl}_{3}$ & 163 & 6.8 & 2.4 & 3.10 & direct & $0.43 / 1.49$ & 68021 \\
\hline $\mathrm{Gd}_{3} \mathrm{InSe}_{6}$ & 58 & 7.2 & 7.4 & 0.67 & direct & $0.65 / 1.08$ & 280242 \\
\hline $\mathrm{HfO}_{2}$ & 225 & 10.4 & 2.3 & 3.71 & direct & $1.69 / 1.03$ & 53033 \\
\hline $\mathrm{HfO}_{3} \mathrm{~Pb}$ & 55 & 10.2 & 1.7 & 2.27 & direct & $0.43 / 1.15$ & 52030 \\
\hline $\mathrm{HgI}_{6} \mathrm{Tl}_{4}$ & 128 & 7.2 & 2.7 & 1.19 & direct & $0.49 / 1.14$ & 14018 \\
\hline $\mathrm{HgO}_{3} \mathrm{Ti}$ & 161 & 8.7 & 2.4 & 1.25 & direct & $0.57 / 1.01$ & 19005 \\
\hline $\mathrm{HgO}_{4} \mathrm{~W}$ & 15 & 9.2 & 2.0 & 2.20 & direct & $0.44 / 0.73$ & 280911 \\
\hline $\mathrm{Hg}_{2} \mathrm{O}_{3} \mathrm{Se}$ & 14 & 8.0 & 2.3 & 2.25 & direct & $0.67 / 0.65$ & 412302 \\
\hline $\mathrm{Hg}_{4} \mathrm{~N}_{2} \mathrm{O}_{8}$ & 14 & 7.5 & 2.2 & 1.70 & direct & $0.57 / 0.66$ & 59156 \\
\hline $\mathrm{Hg}_{6} \mathrm{O}_{7} \mathrm{Si}_{2}$ & 12 & 9.1 & 1.8 & 1.56 & direct & $0.47 / 1.01$ & 69123 \\
\hline $\mathrm{ISe}_{2} \mathrm{Tl}_{5}$ & 140 & 8.6 & 1.9 & 0.68 & direct & $0.74 / 0.74$ & 49524 \\
\hline ITl & 225 & 6.6 & 2.8 & 1.81 & direct & $1.89 / 2.96$ & 60491 \\
\hline $\mathrm{I}_{4} \mathrm{STl}_{6}$ & 128 & 7.2 & 2.4 & 1.61 & direct & $0.65 / 0.79$ & 29265 \\
\hline $\mathrm{I}_{4} \mathrm{SeTl}_{6}$ & 128 & 7.4 & 2.4 & 1.53 & direct & $0.64 / 0.82$ & 40520 \\
\hline $\mathrm{O}_{2} \mathrm{Sn}$ & 136 & 6.9 & 11.8 & 0.52 & direct & $1.27 / 5.15$ & 39178 \\
\hline $\mathrm{O}_{2} \mathrm{Sn}$ & 58 & 7.4 & 11.1 & 1.47 & direct & $1.08 / 5.42$ & 56675 \\
\hline $\mathrm{O}_{3} \mathrm{SbTl}$ & 163 & 7.1 & 3.0 & 1.88 & direct & $0.77 / 0.96$ & 4123 \\
\hline $\mathrm{O}_{3} \mathrm{~W}$ & 7 & 7.4 & 3.1 & 1.50 & direct & $0.42 / 1.64$ & 84144 \\
\hline $\mathrm{O}_{4} \mathrm{~Pb}_{3}$ & 117 & 8.7 & 1.6 & 1.16 & direct & $0.63 / 1.61$ & 29094 \\
\hline $\mathrm{O}_{4} \mathrm{~Pb}_{3}$ & 135 & 8.9 & 1.6 & 0.64 & direct & $0.73 / 1.51$ & 22325 \\
\hline
\end{tabular}


Table 3.2

Cerium activated materials

\begin{tabular}{|c|c|c|c|c|c|c|c|}
\hline Material & Spgrp & $\rho$ & PAL & $E_{\mathrm{g}}$ & Gap type & wbw/cbw & ICSD no. \\
\hline $\mathrm{AlLaO}_{3}$ & 167 & 6.5 & 9.9 & 3.68 & in-direct & $0.29 / 0.66$ & 90536 \\
\hline $\mathrm{AlO}_{3} \mathrm{~Tb}$ & 62 & 7.5 & 5.3 & 6.38 & direct & $0.32 / 2.38$ & 84422 \\
\hline $\mathrm{Al}_{2} \mathrm{Gd}_{2} \mathrm{O}_{7} \mathrm{Sr}$ & 139 & 6.9 & 7.2 & 5.90 & direct & $0.31 / 3.27$ & 33580 \\
\hline $\mathrm{Al}_{3} \mathrm{~F}_{19} \mathrm{~Pb}_{5}$ & 108 & 6.8 & 2.7 & 4.56 & in-direct & $0.24 / 0.26$ & 203224 \\
\hline $\mathrm{Al}_{3} \mathrm{~F}_{19} \mathrm{~Pb}_{5}$ & 140 & 6.7 & 2.8 & 4.18 & in-direct & $0.21 / 0.41$ & 96597 \\
\hline $\mathrm{Al}_{3} \mathrm{~F}_{19} \mathrm{~Pb}_{5}$ & 87 & 6.7 & 2.8 & 4.37 & in-direct & $0.19 / 0.33$ & 80105 \\
\hline $\mathrm{AsBiO}_{4}$ & 88 & 7.7 & 2.6 & 3.03 & in-direct & $0.25 / 0.70$ & 30636 \\
\hline $\mathrm{AsLuO}_{4}$ & 141 & 6.9 & 5.0 & 3.40 & direct & $0.84 / 1.92$ & 2506 \\
\hline $\mathrm{BGaO}_{4} \mathrm{~Pb}$ & 62 & 6.9 & 3.2 & 3.28 & in-direct & $0.58 / 0.90$ & 279600 \\
\hline $\mathrm{BLuO}_{3}$ & 167 & 6.9 & 3.9 & 5.27 & in-direct & $0.34 / 0.84$ & 16525 \\
\hline $\mathrm{BaBeLa}_{2} \mathrm{O}_{5}$ & 14 & 6.6 & 7.9 & 3.78 & in-direct & $0.36 / 0.16$ & 65292 \\
\hline $\mathrm{BaF}_{2}$ & 62 & 6.7 & 8.6 & 5.52 & in-direct & $0.92 / 2.43$ & 41651 \\
\hline $\mathrm{BaO}_{3} \mathrm{~Tb}$ & 62 & 7.3 & 5.3 & 4.45 & direct & $1.02 / 1.96$ & 86736 \\
\hline $\mathrm{BaO}_{4} \mathrm{~Tb}_{2}$ & 62 & 7.8 & 4.5 & 3.89 & in-direct & $0.15 / 1.83$ & 78661 \\
\hline $\mathrm{BaO}_{5} \mathrm{~Tb}_{2} \mathrm{Zn}$ & 62 & 7.8 & 5.1 & 3.72 & direct & $0.38 / 1.15$ & 69721 \\
\hline $\mathrm{Ba}_{2} \mathrm{Ce}_{0.75} \mathrm{O}_{6} \mathrm{Sb}$ & 139 & 6.5 & 8.6 & 4.00 & in-direct & $0.49 / 0.81$ & 72522 \\
\hline $\mathrm{Ba}_{2} \mathrm{EuO}_{6} \mathrm{Sb}$ & 225 & 7.0 & 7.0 & 4.12 & in-direct & $0.30 / 1.26$ & 38330 \\
\hline $\mathrm{Ba}_{2} \mathrm{GdO}_{6} \mathrm{Sb}$ & 225 & 7.1 & 6.8 & 3.49 & direct & $0.37 / 1.56$ & 38331 \\
\hline $\mathrm{Ba}_{2} \mathrm{O}_{6} \mathrm{SbTb}$ & 225 & 7.2 & 6.5 & 4.18 & direct & $0.32 / 1.27$ & 38332 \\
\hline $\mathrm{Ba}_{2} \mathrm{O}_{6} \mathrm{SbYb}$ & 225 & 7.5 & 5.4 & 4.19 & direct & $0.35 / 1.44$ & 38336 \\
\hline $\mathrm{Ba}_{2} \mathrm{O}_{6} \mathrm{TaYb}$ & 225 & 8.2 & 3.7 & 3.49 & in-direct & $0.38 / 0.83$ & 91001 \\
\hline $\mathrm{Ba}_{2} \mathrm{O}_{6} \mathrm{WZn}$ & 225 & 7.7 & 5.0 & 3.37 & in-direct & $0.31 / 0.56$ & 24983 \\
\hline $\mathrm{Ba}_{3} \mathrm{NiO}_{9} \mathrm{Ru}_{2}$ & 194 & 6.8 & 10.6 & 3.97 & direct & $0.09 / 1.73$ & 50832 \\
\hline $\mathrm{Ba}_{4} \mathrm{O}_{10} \mathrm{Ru}_{3}$ & 64 & 6.7 & 9.9 & 4.72 & in-direct & $0.12 / 0.74$ & 90902 \\
\hline $\mathrm{BeF}_{4} \mathrm{~Pb}$ & 62 & 6.8 & 2.7 & 4.34 & in-direct & $0.19 / 0.53$ & 24568 \\
\hline $\mathrm{BiF}_{3}$ & 62 & 7.9 & 2.0 & 3.81 & in-direct & $0.58 / 0.68$ & 1269 \\
\hline $\mathrm{Bi}_{4} \mathrm{Ge}_{3} \mathrm{O}_{12}$ & 220 & 7.1 & 2.6 & 3.26 & in-direct & $0.22 / 0.32$ & 39231 \\
\hline $\mathrm{Bi}_{4} \mathrm{O}_{12} \mathrm{Si}_{3}$ & 220 & 6.8 & 2.4 & 3.58 & in-direct & $0.37 / 0.24$ & 84519 \\
\hline $\mathrm{BiO}_{4} \mathrm{~V}$ & 15 & 7.0 & 2.8 & 3.38 & in-direct & $0.39 / 0.51$ & 31549 \\
\hline BrGdO & 129 & 6.8 & 6.4 & 4.16 & direct & $1.08 / 0.99$ & 41071 \\
\hline $\mathrm{CaLu}_{2} \mathrm{O}_{4}$ & 62 & 8.1 & 3.2 & 3.49 & in-direct & $0.42 / 1.23$ & 15125 \\
\hline $\mathrm{CaO}_{11} \mathrm{Ta}_{4}$ & 182 & 7.6 & 3.3 & 3.08 & in-direct & $0.18 / 0.38$ & 1854 \\
\hline $\mathrm{CaO}_{4} \mathrm{Yb}_{2}$ & 62 & 8.0 & 3.4 & 4.38 & direct & $0.22 / 1.65$ & 27312 \\
\hline $\mathrm{CaO}_{6} \mathrm{Ta}_{2}$ & 62 & 7.4 & 3.5 & 3.15 & in-direct & $0.17 / 0.80$ & 24091 \\
\hline $\mathrm{CeO}_{2}$ & 225 & 7.2 & 6.8 & 5.62 & in-direct & $0.48 / 1.38$ & 28753 \\
\hline $\mathrm{Ce}_{2} \mathrm{O}_{3}$ & 164 & 6.5 & 7.1 & 3.61 & in-direct & $0.43 / 1.36$ & 96197 \\
\hline ClGdO & 129 & 6.7 & 5.8 & 5.13 & direct & $0.72 / 1.13$ & 59232 \\
\hline $\mathrm{F}_{3} \mathrm{La}$ & 139 & 7.0 & 8.5 & 5.40 & in-direct & $0.88 / 0.40$ & 96133 \\
\hline $\mathrm{F}_{6} \mathrm{SnTl}_{2}$ & 164 & 6.8 & 2.9 & 4.03 & direct & $0.78 / 1.29$ & 410801 \\
\hline $\mathrm{F}_{7} \mathrm{SiTl}_{3}$ & 163 & 6.8 & 2.4 & 3.10 & direct & $0.43 / 1.49$ & 68021 \\
\hline $\mathrm{GaLaO}_{3}$ & 161 & 7.0 & 10.4 & 3.27 & in-direct & $0.18 / 0.78$ & 51039 \\
\hline $\mathrm{GaLaO}_{3}$ & 167 & 6.9 & 10.5 & 3.01 & in-direct & $0.21 / 1.02$ & 51286 \\
\hline $\mathrm{GaLaO}_{3}$ & 62 & 7.2 & 10.1 & 3.24 & direct & $0.51 / 0.56$ & 79662 \\
\hline $\mathrm{Gd}_{2} \mathrm{GeO}_{5}$ & 14 & 7.1 & 5.9 & 3.76 & direct & $0.24 / 1.16$ & 61372 \\
\hline $\mathrm{Gd}_{2} \mathrm{O}_{3}$ & 206 & 7.6 & 4.4 & 3.20 & in-direct & $0.23 / 1.50$ & 40473 \\
\hline $\mathrm{Gd}_{2} \mathrm{O}_{5} \mathrm{Si}$ & 14 & 6.8 & 5.7 & 4.71 & in-direct & $0.17 / 0.78$ & 27728 \\
\hline $\mathrm{Gd}_{3} \mathrm{O}_{12} \mathrm{Sb}_{5}$ & 217 & 6.6 & 7.3 & 3.16 & in-direct & $0.13 / 0.17$ & 65147 \\
\hline $\mathrm{Ge}_{2} \mathrm{Lu}_{2} \mathrm{O}_{7}$ & 92 & 7.4 & 4.6 & 3.55 & in-direct & $0.12 / 1.53$ & 39929 \\
\hline $\mathrm{Ge}_{4} \mathrm{Lu}_{6} \mathrm{O}_{17}$ & 13 & 7.4 & 4.1 & 3.85 & in-direct & $0.16 / 1.38$ & 39790 \\
\hline $\mathrm{InO}_{4} \mathrm{Ta}$ & 13 & 8.3 & 3.9 & 3.54 & in-direct & $0.24 / 0.60$ & 72569 \\
\hline $\mathrm{KO}_{8} \mathrm{~W}_{2} \mathrm{Y}$ & 15 & 6.6 & 4.6 & 3.32 & direct & $0.18 / 0.22$ & 90378 \\
\hline $\mathrm{LaO}_{3} \mathrm{Yb}$ & 33 & 8.2 & 3.8 & 4.30 & direct & $0.25 / 0.35$ & 30399 \\
\hline $\mathrm{La}_{2} \mathrm{LiO}_{6} \mathrm{Sb}$ & 14 & 6.5 & 9.0 & 3.82 & in-direct & $0.21 / 0.74$ & 72202 \\
\hline $\mathrm{La}_{2} \mathrm{O}_{3}$ & 150 & 6.6 & 7.5 & 3.16 & in-direct & $0.75 / 1.13$ & 56166 \\
\hline $\mathrm{La}_{2} \mathrm{O}_{3}$ & 164 & 6.5 & 7.6 & 3.74 & in-direct & $0.38 / 0.83$ & 96196 \\
\hline $\mathrm{LuO}_{2} \mathrm{Rb}$ & 166 & 7.6 & 4.2 & 3.48 & in-direct & $0.53 / 1.83$ & 15164 \\
\hline $\mathrm{LuO}_{4} \mathrm{P}$ & 141 & 6.5 & 4.7 & 5.54 & & $0.89 / 1.57$ & 79761 \\
\hline $\mathrm{Lu}_{2} \mathrm{O}_{3}$ & 206 & 9.4 & 2.4 & 3.77 & in-direct & $0.28 / 1.21$ & 40471 \\
\hline $\mathrm{Lu}_{2} \mathrm{O}_{5} \mathrm{Si}$ & 14 & 7.9 & 3.3 & 4.65 & in-direct & $0.24 / 1.12$ & 89624 \\
\hline $\mathrm{O}_{11} \mathrm{SrTa}_{4}$ & 182 & 7.8 & 3.3 & 3.07 & in-direct & $0.19 / 0.37$ & 79704 \\
\hline $\mathrm{O}_{12} \mathrm{Sb}_{5} \mathrm{Yb}_{3}$ & 217 & 7.0 & 5.4 & 3.15 & in-direct & $0.09 / 0.25$ & 20945 \\
\hline $\mathrm{O}_{4} \mathrm{STl}_{2}$ & 62 & 6.8 & 2.4 & 3.68 & in-direct & $0.31 / 0.61$ & 27440 \\
\hline $\mathrm{O}_{4} \mathrm{SeTl}_{2}$ & 62 & 7.0 & 2.5 & 3.46 & in-direct & $0.22 / 0.58$ & 73411 \\
\hline $\mathrm{O}_{4} \mathrm{SrYb}_{2}$ & 62 & 8.4 & 3.5 & 4.78 & direct & $0.19 / 1.65$ & 15123 \\
\hline AgLaOS & 129 & 6.6 & 9.4 & 1.18 & direct & $1.30 / 1.96$ & 15530 \\
\hline $\mathrm{AsBrHg}_{3} \mathrm{~S}_{4}$ & 186 & 6.6 & 3.1 & 1.28 & in-direct & $0.56 / 1.34$ & 280330 \\
\hline $\mathrm{BiBrS}$ & 62 & 6.5 & 2.8 & 1.47 & in-direct & $0.61 / 1.32$ & 31389 \\
\hline BiIS & 62 & 6.8 & 2.8 & 1.16 & in-direct & $0.62 / 1.34$ & 23631 \\
\hline $\mathrm{Bi}_{2} \mathrm{~S}_{3}$ & 62 & 6.8 & 2.2 & 1.04 & in-direct & $0.59 / 0.97$ & 201066 \\
\hline FLuS & 166 & 6.7 & 3.9 & 2.40 & in-direct & $1.24 / 1.35$ & 89549 \\
\hline
\end{tabular}

\section{References}

1] <http://gurka.fysik.uu.se/esp/>.

[2] M. Cohen, Annual Review of Material Science 30 (2000) 1-26.

[3] G.B. Olson, Science 288 (5468) (2000) 993-998.

4] G. Andersson, T. Burkert, P. Warnicke, M. Björck, B. Sanyal, C. Chacon, C. Zlotea, L. Nordström, P. Nordblad, O. Eriksson, Physical Review Letters 96 (3) (2006) 037205.

[5] T. Burkert, L. Nordström, O. Eriksson, O. Heinonen, Physical Review Letters 93 (2) (2004) 027203

[6] G.L.W. Hart, V. Blum, M.J. Walorski, A. Zunger, Nature Materials 4 (5) (2005) 391-394.

[7] C.C. Fischer, K.J. Tibbetts, D. Morgan, G. Ceder, Nature Materials 5 (2006) 641646.

[8] ICSD Inorganic Crystal Structure Database, FIZ Karlsruhe. <http://www.fizkarlsruhe.de/icsd.html>.

[9] J.M. Wills, O. Eriksson, M. Alouani, D.L. Price, Electronic Structure and Physical Properties of solids: The uses of the LMTO method, Springer Verlag, Berlin, 2000.

[10] <http://databases.fysik.dtu.dk/>.

[11] <http://caldb.nims.go.jp/>.

[12] <http://cst-www.nrl.navy.mil/>

[13] <http://ptp.ipap.jp/link?PTPS/138/755/>.

[14] C.J. Bradley, A.P. Cracknell, The Mathematical Theory of Symmetry in Solids: Representation Theory for Point Groups and Space Groups, Clarendon press, Oxford, 1972.

[15] W. Lehmann, Solid-State Electronics 9 (1966) 1107-1110.

[16] G.F. Knoll, Radiation Detection and Measurement, John Wiley and Sons, 2000.

[17] M.M. Atalla, Scientific Rept. no. 8, 1964, p. AD0447260.

[18] D.R. Lide (Ed.), CRC Handbook of Chemistry and Physics, Internet version, 88 th ed., Taylor and Francis, Boca Raton, FL, 2007.

[19] W. Yen, M. Raukas, S. Basun, W. van Schaik, U. Happek, Journal of Luminescence 69 (1996) 287.

[20] P. Dorenbos, Journal of Luminescence 91 (2000) 155-176. 